\title{
On the Instrumental Value of Vagueness in the Law*
}

\section{Hrafn Asgeirsson}

It is natural to think that law ought not to be vague. After all, law is supposed to guide conduct, and vague law seems poorly suited to do that. Contrary to this common impression, however, a number of authors have argued that vagueness in the law is sometimes a good thing, because it is a means to achieving certain valuable legislative ends. In this article, I argue that many authors-including Timothy Endicott and Jeremy Waldron-wrongly associate vagueness with instrumental roles that are really played by a closely related semantic phenomenon.

It is natural to think that law ought not to be vague. After all, law is supposed to guide conduct, and vague law seems poorly suited to do that. Contrary to this common impression, however, a number of authors have recently argued that vagueness in the law is sometimes a good thing, because it is - in one way or another - a means to achieving certain valuable ends. Timothy Endicott argues, for example, that vagueness in the law is valuable in virtue of being a necessary means to adequately regulating certain forms of conduct, while Jeremy Waldron argues that it is valuable because it is a facilitating — or partial - means to invoking people's capacity for practical deliberation in a special way. On

* This article was completed while I was a research fellow at Monash University, Faculty of Law, supported by a grant from the Australian Research Council. I would like to thank the participants of the Center for the Study of Mind in Nature Colloquium Series in Oslo for helpful discussion of an earlier version of this article, in particular Nicholas Allott, Andreas Stokke, Anders Nes, and Olav Gjelsvik. I would also like to thank the participants of the Monash Work in Progress Series for many valuable comments, in particular Lloyd Humberstone and Alistair Wilson, as well as audience members at the Blurred Boundaries Conference on Vagueness and Law and at San Francisco State University. I am particularly indebted to Andrei Marmor and Gideon Yaffe for valuable comments on several drafts and to my colleague Dale Smith for helpful discussions about key parts of the article. And last but not least, I would like to thank Henry S. Richardson, the editors, and two reviewers at Ethics for their helpful comments.

Ethics 125 (January 2015): 425-448

(C) 2015 by The University of Chicago. All rights reserved. 0014-1704/2015/12502-0002\$10.00 
views like these, then, vagueness in the law is - or at least can be - instrumentally valuable. ${ }^{1}$

In this article, I want to point out what I take to be a rather common mistake underlying the attribution of instrumental value to vagueness in the law. Although I think that it does in fact have some such value, ${ }^{2}$ it seems to me that many authors (including Endicott and Waldron) wrongly associate vagueness with instrumental roles that are really played by a closely related semantic phenomenon-what I call incommensurate multidimensionality. Incommensurate multidimensionality entails vagueness, so it is perhaps unsurprising that the former is sometimes mistaken for the latter. Such a mistake, however, has significant consequences when it comes to the proper attribution of instrumental value, because value only "transmits" from ends to means but not to necessary consequences of those means.

I begin by explaining very briefly what kind of vagueness is supposed to be a valuable feature of law and how incommensurate multidimensionality entails such vagueness. Next, I examine the arguments made by Endicott and Waldron, arguing that their key premises are based on a mistake-incommensurate multidimensionality, rather than vagueness, facilitates the relevant legal ends. I devote most of my discussion to Endicott's argument and then go on to show how my critique carries over to Waldron's. After that, I consider what seems like the most natural general response to my critique: to argue that because using vague terms is a necessary consequence of using multidimensional terms, using the former is actually a necessary means to using the latter. Given the transitivity of the is-a-means-to relation, it would follow that value does in fact transmit from the relevant legislative ends to vagueness. I argue that there is a general reason why this strategy fails: it is not generally true that if something is a necessary consequence of a means to some end, then it is also a means to that end. Finally, I note that-independently of any considerations of means and ends - Standard Deontic Logic (SDL) validates a principle that, given my concession that incommensurate multidimensionality is sometimes a good thing, seems to force on me the conclusion that vagueness is sometimes a good thing, too. I mention in brief a number of ways to avoid this conclusion, in order to acknowledge that - and illustrate how - in making claims about how to reason with value statements, one incurs significant commitments in the logic of value.

1. Throughout the article, 'instrumental value' refers to the value that something has in virtue of its being a means to something good-in this sense, then, not all means have instrumental value.

2. See, e.g., Hrafn Asgeirsson, "Vagueness and Power-Delegation in Law: A Reply to Sorensen," in Current Legal Issues: Law and Language, ed. Michael Freeman and Fiona Smith (Oxford: Oxford University Press, 2013), 344-55. 


\section{INCOMMENSURATE MULTIDIMENSIONALITY, EXTRAVAGANT VAGUENESS, AND ENDICOTT'S ARGUMENT FROM INSTRUMENTAL NECESSITY}

Many natural language expressions are associated with multiple dimensions; consider, for example, the term 'crowd', the proper application of which (in a context) depends on the number of people and the density of the relevant gathering. It is also quite common that two or more of the dimensions of such expressions are incommensurate - that is, to use Timothy Endicott's phrase, they correspond to "attributes that cannot be measured in common units." 3 There is no nonarbitrary way, for example, to measure how the decrease in the number of people in a gathering can be offset by an increase in its density so that it still counts as a crowd.

According to Endicott, incommensurate multidimensionality entails vagueness. The reason, he says, is that incommensurability across associated dimensions entails partially defined comparatives ( 'is more/less $F$ than'), which in turn entail the absence of a sharp boundary between the relevant predicate's determinate extension and determinate antiextension (i.e., there is no sharp boundary between the $F$ s and the non$\left.F_{\mathrm{s}}\right) .{ }^{4}$ And if there is no such boundary, then the relevant predicate is vague. Further, as the number of incommensurate dimensions increases, the indeterminate cases will start to crowd out the determinate ones, and, eventually, we get what Endicott calls extravagant vagueness, which he primarily associates with normative terms. Paradigmatic examples of extravagantly vague terms in the law include, for example, 'neglect' and 'reasonable', both of which are associated with multiple incommensurate dimensions, and both of which are common in tort, contract, and administrative law (and the latter even in commercial law). ${ }^{5}$

3. Timothy Endicott, Vaqueness in Law (Oxford: Oxford University Press, 2000), 42. Two attributes can fail to be measurable in a common unit in at least two ways: (i) the attributes may each have a natural numerical ordering, but there is no common unit to which the relevant scales can nonarbitrarily be reduced, and (ii) the attributes may not have any natural numerical ordering.

4. See ibid., 36 (esp. n. 6). The basic idea is that if the attributes associated with a term cannot be measured in common units, then for every (actual or possible) $x$, there will be some (actual or possible) $y$, such that it is indeterminate whether $x$ is more/less $F$ than $y$. If so, then there will be no $x$ such that (i) for every $y$ that is $F, x$ is less $F$ than, or just as $F$ as, $y$, and (ii) for every $z$ that is not $F, x$ is more $F$ than $z$.

5. In addition to it being unsettled how the relevant dimensions of such terms "interact," with respect to their proper application, it is often significantly unsettled exactly what the relevant dimensions are. Thanks to an editor at Ethics for pressing me to address this point. 
Endicott argues that extravagant vagueness of this kind is instrumentally valuable to law. The primary motivation for this conclusion is the following claim: extravagant vagueness is a necessary means for achieving general regulation of a widely varying range of conduct. ${ }^{6}$ In many legislative contexts, he says, precise schemes of regulation are impossible, and so the only means for regulating the relevant forms of human conduct is to issue vague norms. Thus, according to Endicott, lawmakers sometimes have to use extravagantly vague terms, if they wish to regulate. In order, for example, to adequately prevent, and punish, conduct that is especially damaging to children, he says, the law must use terms like 'neglect' and 'abandoned' (or approximate - and usually nonexhaustive-definitions thereof which are themselves extravagantly vague). Assuming - as we certainly can in this case-that it is valuable to prevent such conduct, it follows that extravagant vagueness is an instrumentally valuable feature of law, despite the fact that such vagueness is likely both to produce borderline cases that are practically consequential and to generate serious and deep disputes over the relevant norm's principles of application. Or so Endicott argues.

Let us say that the law adequately regulates undesirable conduct if it prevents an adequate number of instances of it and adequately punishes the instances that do occur. We can then analyze Endicott's argument in the following way: ${ }^{7}$

P1. Adequately regulating conduct that is especially damaging to children is good.

P2. Vagueness in the law is a necessary means to adequately regulating conduct that is especially damaging to children.

P3. Value transmits from ends to means.

C. Vagueness in the law is (sometimes) instrumentally good.

I am prepared to accept the argument as valid, and I certainly do not wish to dispute P1. The principle P3 - which I take to be an axiom in the logic of value - is also pretty solid, so long as we take it to transmit pro tanto value: if $x$ is all-things-considered good and $y$ is a necessary means to $x$, then $x$ is pro tanto instrumentally good. ${ }^{8}$ What I have to do, then, is to

6. See Timothy Endicott, "The Value of Vagueness," in Philosophical Foundations of Language in the Law, ed. Andrei Marmor and Scott Soames (Oxford: Oxford University Press, 2011), $14-30,28$.

7. Thanks to Olav Gjelsvik for helpful discussion about Endicott's argument.

8. Thanks to Henry S. Richardson and an editor at Ethics for helpful comments regarding P3. Note that one could choose to limit the conclusion to vagueness in the law being pro tanto good, subject to possible outweighing, or one could go further and agree with Endicott that its pro tanto goodness outweighs whatever pro tanto badness it may have, concluding - as Endicott does - that vagueness in the law is (sometimes) good, all things con- 
cast doubt on P2: that is, to show that - despite appearances to the contrary - vagueness is not a necessary means to adequately regulating conduct that is especially damaging to children. My focus will be on the term 'neglect', as it is used in child care law, since this is one of Endicott's favorite examples of vague terms that lawmakers have to use, if they are to properly regulate human affairs. ${ }^{9}$

\section{INCOMMENSURATE MULTIDIMENSIONALITY IS DOING THE REAL WORK}

According to Endicott, the issue that is immediately relevant to determining the instrumental value of vagueness in the law is that terms like 'neglect' cannot possibly be replaced by precise phrases that are sufficiently similar to these terms in their extension, or by any disjunctions thereof. In general, only terms that have one or more totally ordered dimensions, or that are otherwise significantly correlated with such an attribute, can be so replaced. 'Citizens are required to drive safely', for example, can be replaced with 'Citizens are required to drive at no more than $n$ mph' in tandem with a host of other more or less precise rules, because speed is such a weighty factor in safe driving, and the resulting scheme of laws can still be said to have the purpose of preventing automobilerelated accidents/injuries/damage. This is similarly true with 'Only mature citizens may vote' and 'Only citizens older than $n$ years of age may vote' (even though age is only a significantly correlated attribute, since age is not something in virtue of which one counts as mature).

Vague terms or phrases that are not associated with any attribute that can be quantitatively measured, on the other hand, do not generally admit of replacement by relatively precise alternatives, nor do terms that are associated with a relatively insignificant proportion of such dimensions, since - in most cases - the resulting regulation could not properly be said to be a regulation of the conduct in question (more on this below, in Sec. IV). Arguably, 'neglect' falls in the latter category, since, although time (spent with or away from one's children) and age (of, say, babysitters) are certainly relevant attributes, these dimensions-along with other totally ordered dimensions - do not suffice to make for an ade-

sidered. Note also that I leave it open how much value P3 transmits from ends to means. For a valuable discussion of transmission principles for 'ought'/ reasons and related problems, see Niko Kolodny, "Instrumental Reasons," forthcoming in The Oxford Handbook of Reasons and Normativity, ed. Daniel Star (Oxford: Oxford University Press).

9. I should also note that my discussion owes a great deal both to Kolodny, "Instrumental Reasons," and to Scott Soames, "What Vagueness and Inconsistency Tell Us about Interpretation," in Marmor and Soames, Philosophical Foundations of Language in the Law, 31-57. 
quate replacement. In these cases, vagueness is indeed necessary for the relevant regulatory ends. But that, I hope to show, does not suffice for vagueness to have value, even if the ends in question are valuable.

Let me begin by saying that what lawmakers have to do in order to regulate a wide variety of conduct with a general standard is not-in the first instance-to use terms that are vague. Rather, it is to use broad general terms associated with multiple incommensurate dimensions, or perhaps to use approximate (and usually nonexhaustive) definitions thereof which are themselves highly general and multidimensional. (It is important to note that nonexhaustive definitions do not replace their definienda; rather, they are meant to be guidelines for application.) Endicott even indicates as much in at least two places. He claims, for example, that the relevant issue regarding negligence law is the "sheer, mindboggling variety of ways in which people can create more or less unreasonable risks to other people" and that the relevant issue regarding child care law is the "daunting variety of things that a child needs from its parents [which] corresponds to a wide variety of ways in which a parent may more or less neglect a child."10

Now, I think that Endicott is right that extravagantly vague laws generally do not have any relatively precise replacements, since terms tend to be extravagantly vague due to the fact that they have multiple dimensions that cannot be measured in a common metric (and some are bound to be impossible to measure in any reasonable way, at least cardinally). But I think he is wrong in maintaining that this is the issue that is relevant to determining whether vagueness has value in virtue of being a necessary means. The reason, I will argue, is that vagueness is not the semantic feature that helps bring about this "general regulation of a widely varying range of conduct."11 Rather, incommensurate multidimensionality is doing the real work.

To see this, consider the following general features of the relevant lawmaking scenarios, where, again, the law adequately regulates undesirable conduct if it prevents an adequate number of instances of it and adequately punishes the instances that do occur. First, lawmakers need/want to adequately regulate a (possibly open-ended) set of multiple related types of behavior. Second, there exists a term denoting the relevant set, a highly general term with multiple incommensurate dimensions. ${ }^{12}$ Third, it is not possible for lawmakers to compile a list-

10. Endicott, "Value of Vagueness," 25, 24.

11. Ibid., 28.

12. Note that worries about family resemblances are premature, since it suffices for this characterization that, for example, 'game' denotes a property that is informative and necessary of all instances of every subtype of game - such as chess, solitaire, and golf. It is only 
precise or not - of less general terms, such that (disjunctively) they adequately cover the relevant set, vis-à-vis the relevant legislative purposes.

In Endicott's favored example, for instance, lawmakers want to prohibit certain forms of conduct in order to prevent certain types of harm to children (and to punish instances that do occur), namely, (something like) those types that constitute unreasonable failure on behalf of parents to pay attention to the needs that their children have in virtue of their parent-child relationship. And indeed there exists a term that covers the relevant forms of behavior - namely, 'neglect'. Due to the nature of such conduct, however, it is not possible for lawmakers to devise a list of less general terms-precise or not-that disjunctively covers an adequate amount of the relevant behavior (i.e., an adequately coextensive list of action-type terms). As Scott Soames notes: "one who undertook the task of more precisely delineating either [the class of clear neglect or the class of clear nonneglect] using only more highly-focused language designating specific behavior - about the regularity and content of meals, frequency of trips to doctors, time with parents, age of baby-sitters, and the likewould ... find it stupefying at best, and practically impossible, at worst." 13

If lawmakers were to try to use any such attempted list, they would likely get things gravely wrong; they would probably end up failing to prevent (and punish) a significant amount of harmful conduct as well as prevent (and punish) a significant amount of nonharmful conduct. That is, any attempt to come up with a list would result in excessively over- and underinclusive regulation. ${ }^{14}$ Lawmakers, then, should not attempt to specify the set of action types intended to be prohibited. Given that they want to adequately prevent (and punish) harm that is especially damaging to children, they should rather use the term 'neglect' or some approximate - and presumably nonexhaustive- high-level definition thereof..$^{15}$

\section{THE IMPOSSIBILITY OF SPECIFICATION}

There are, of course, a variety of ways in which something can be impossible, and so far I haven't said anything about in what sense it is impossible for lawmakers to devise an adequate, more specific, list of terms. Is

in relation to the exact nature of this property that issues about family resemblances come up, since no one would deny that, necessarily, chess, solitaire, and golf are all games.

13. Soames, "Vagueness and Inconsistency," 40.

14. The law does have some tools for handling errors like these-such as the necessity defense; more on this in Sec. IV below.

15. That, for example, is what UK lawmakers did when they wrote the Child and Young Persons Act (1933); Endicott, "Value of Vagueness," 24. 
it metaphysically impossible or epistemically impossible or perhaps simply practically impossible?

It may be tempting to think that the impossibility of compiling an informative list of subtypes of neglect has to do with the contextsensitive nature of evaluation. And presumably it does have something to do with it. However, the immediate issue of unspecifiability has nothing to do with evaluation, as such. To see this, let us say that someone who utters 'The Smiths have been neglectful toward their child' succeeds in communicating the proposition that the Smiths have unreasonably failed to pay attention to the needs of their child. ${ }^{16}$ We can-at least for practical purposes - separate the evaluative aspect of this (rough, but sufficient) analysis from the descriptive aspect and focus just on the latter (i.e., on the proposition that the Smiths failed to pay attention to the needs of their child). With respect to unspecifiability, 'neglect' is in an important sense no different from many purely descriptive terms: just as there is a vast variety of ways, for example, in which people can walk to work or use a firearm, so there is a vast variety of ways in which people can, as parents, fail to pay attention to the needs of their children (in part due to the diversity of a child's needs). In general, there is nothing distinctively evaluative about the inability to list exhaustively the ways in which one can realize a given action type, even if the relevant term is properly characterized as evaluative; we could repeat this line of reasoning, for example, with 'cruel', 'lewd', 'unjust', and so forth.

Now, this inability could merely be practical. Perhaps there is a finite number of ways in which parents can fail to pay attention to the needs of their children, but for practical reasons we just can't list them. Or there is a countably infinite number of ways, and so it is impossible to know what a complete list looks like. If so, then it will of course also be impossible to construct one. Or perhaps the number is uncountably infinite, in which case any sort of complete list is impossible (try, e.g., to imagine counting possible worlds), let alone knowable or humanly constructible.

To be sure, when it comes to normative terms, there is a furtherpotentially significant-complication: we are only interested in those instantiations of the relevant types that have the further property of being unjustified (whatever property that turns out to be). If parents, for example, for justifying reasons do not feed their children regular

16. I say 'communicates' because I wish to remain neutral about the "linguistic location" of the evaluative aspect of such an utterance. That is, nothing turns on if the evaluative aspect is part of the semantics of the term or if it gets attached pragmatically (by way of pragmatic enrichment, implicature, or presupposition). 
nutritious meals - say, during a widespread famine - then presumably we wouldn't complain that they are being neglectful. ${ }^{17}$ So, what we are ultimately after is a list of action types in (types of) circumstances: A1 in C1, A2 in C2, and so on. Each item on this more complicated list, then, is what is correctly said to be less general than 'neglect', even if the relation isn't straightforwardly taxonomic (like it is with 'tiger' and 'mammal').

Thus, even if we had a reasonable list of action types that corresponds to the ways in which parents can fail to pay attention to their children's needs, we would need to revise that list so as to include only unreasonable instantiations of those types. And here, we are faced with a problem similar to the immediate one described above, in that we need a list of exceptions, determined by a theory of right and wrong action. Depending on one's metaethical view, however, such a list may be finite, countably infinite, or uncountably infinite. Only if the list of exceptions is finite and practically manageable can we expect an adequate specification of 'neglect'. This is a tall order, and probably not to be expected. As Pekka Väyrynen has pointed out, outside ethics it has not proved promising to provide finite lists of exceptions to ceteris paribus generalizations, and there is no a priori reason to think that ethics is special in that respect. ${ }^{18}$

If what I have said in this section and in the section before it is true, then we have good reason to believe that using terms that are associated with multiple incommensurate dimensions is a necessary means for adequately regulating, for example, conduct that is especially damaging to children. This, of course, does not suffice to show decisively that Endicott's P2 is false, since A's being a necessary means to C does not preclude $\mathrm{B}$ from also being a necessary means to $\mathrm{C}$, but it does very strongly suggest that vagueness is not what is really doing the work, visà-vis the regulation of the relevant forms of conduct. If that is correct, then - at the very least - the support for P2 goes away.

In the next section, I want to tackle an issue that I have left unaddressed so far. I have been taking it pretty much for granted that using a certain set of terms is indeed a necessary means for regulating conduct that is especially damaging to children and that the primary issue

17. Or consider the morality-based motivation for allowing battered mothers to seek a defense of duress or of diminished capacity against prosecution for Failure to Protect.

18. Pekka Väyrynen, "A Theory of Hedged Moral Principles," Oxford Studies in Metaethics 4 (2009): 91-132; citing, e.g., Jerry Fodor, "You Can Fool Some of the People All of the Time, Everything Else Being Equal: Hedged Laws and Psychological Explanations," Mind 100 (1991): 19-34; and Paul Pietroski and Georges Rey, "When Other Things Aren't Equal: Saving Ceteris Paribus Laws from Vacuity," British Journal for the Philosophv of Science 46 (1995): 81-110. 
is what semantic aspect of those terms is doing the work. But, as I hope to show below, it is not obvious that this is true. In many cases, it is better to regulate conduct with terms or phrases that are associated with relatively few dimensions - and which are therefore relatively precise - than with vague multidimensional terms. The question is why this is not also the case when it comes to regulating conduct that is especially damaging to children. Why exactly are there supposed to be no good proxies for terms like 'neglect', as it is used in child care law?

\section{ARE INCOMMENSURATE MULTIDIMENSIONALITY AND- HENCE-VAGUENESS REALLY NECESSARY?}

Let us suppose, on the basis of what I said in the previous section, that it is in fact - at a minimum-practically impossible to compile a list of action types (in circumstances) that is necessarily coextensive with 'neglect'. It is natural to wonder whether this is any different from other forms of conduct that lawmakers have an interest in regulating. Surely, in many cases, lawmakers do the right thing by trying to replace general terms with something more specific-and thus often better action guiding - even if it results in a specification that is likely to be both over- and underinclusive. Sometimes, it is simply better to settle for some sort of rough approximation. When it comes to drinking and voting age, for example, it would make bad sense to formulate the law in terms of maturity. Given the extent to which people would be at the mercy of officials and the cost of evaluating each case, it is better to avoid that mess and make age the legally relevant factor, as was done in the National Minimum Drinking Age Act (23 U.S.C. $\$ 158$ [1984]) and in the Twenty-Sixth Amendment of the US Constitution.

Why shouldn't we do something similar with 'neglect'? Couldn't we, for example, either construct an admittedly underinclusive but manageable list of relevant action types or find some quantifiable aspectsuch as the minimum age of babysitters, minimum number of visits to the doctor per month, minimum number and nutritional value of meals per day, and so on - and rely on available legal tools, such as legal defenses, to mitigate any over- and underinclusiveness? The significance here of settling this issue is that if neither incommensurate multidimensionality nor vagueness is strictly necessary for the relevant lawmaking, then Endicott's P2 is straightforwardly false, and it would be superfluous for me to argue that despite its necessity vagueness does not inherit any value from the relevant ends. In addition, one of the main sources of appeal of Endicott's argument is that it is an argument from instrumental necessity and, accordingly, promises to be significantly stronger than arguments from facilitation. 
In the case of neglect, I do not think it is possible to do away with incommensurate multidimensionality/vagueness in the way suggested, and I think we can see why if we attend to the fact that the relational notion of being an adequate proxy has - for our purposes - two relevant dimensions. Let us say that a term $t_{1}$ is an adequate proxy for a term $t_{2}$ if and only if it is not the case that the product of the number of errors and their disvalue resulting from the use of $t_{1}>$ the product of the number of errors and their disvalue resulting from the use of $t_{2} \cdot{ }^{19}$ What makes the suggestions in the previous paragraph inadequate proxies has, I think, primarily to do with the gravity of the resulting errors - that is, with the gravity of the over- and underinclusiveness (and the limits of legal tools to mitigate these; more on this below). It seems to me that, on any reasonable theory of value, what is at stake in adequately preventing child neglect is considerably weightier than what is at stake in preventing, say, immature people from voting or drinking.

By saying this, I just mean that the interest that children have in not being subject to neglect (underinclusion) and the interest that parents have in not being held legally responsible for morally permissible or excused conduct (overinclusion) is weightier or stronger than any comparable interests that may be present in the context of voting and drinking. If so, then it is reasonable to think that instances of over- and underinclusiveness in the attempt to regulate child neglect will be quite serious. And given that any attempt to provide a fairly specific, but manageable, list of relevant conduct is likely to be widely off the mark, if not entirely so, we can reasonably say that the resulting over- and underinclusiveness would be excessive. Given the number of errors and their disvalue, it is too off the mark to count as a means to the lawmakers' end of adequately preventing and punishing child neglect. This provides, I believe, a reasonable explanation why nothing will make for a relatively precise proxy for 'neglect', as opposed, for example, to 'mature'.

It is worth emphasizing here that whether a term is an adequate proxy for some other term of course depends on a multitude of factors. My argument above, for example, presupposes that subjects, courts, and agencies are more or less competent to respond reasonably to regulation using a term like 'neglect'. But if such regulation were shown to systematically prompt parents, judges, or agency officials to make biased or prejudicial decisions regarding the welfare of children, then it would perhaps no longer be so clear that 'neglect' lacked an adequate proxy. Under such circumstances, we might conceivably do equally well or bet-

19. Note here that ' $t$ ' can denote either what we would normally call a single term or a set thereof. 
ter to try to come up with a relatively specific list of behaviors to prohibit, even if this would in fact result in a significant number of grave errors. Now, as a matter of fact, I do not think that this is the casethere really is no adequate proxy for 'neglect' in child care law, I believe. It is important, however, to stress that adequate proxyhood, as I have defined it, is a comparative relation and that a great variety of things (including, e.g., the competence of officials) may affect whether one term is an adequate proxy for another, because they affect the number and gravity of errors resulting from the use of the relevant terms. ${ }^{20}$

This brings me to another possible objection to my claim that 'neglect' has no adequate proxy, vis-à-vis child care law. I have said that any attempt to provide a fairly specific, but manageable, list of relevant conduct is likely to result in excessive over- and underinclusiveness, given the number of errors and - most significantly - their great disvalue. I have also said, however, that the law does have some tools for handling errors like these-most notably legal defenses that aim at exculpating those who break the law excusably or justifiably (such as Insanity and Necessity, respectively). The potential problem for me here is that if such tools reliably reduce the number of errors, then it makes sense-especially in this particular case, given the emphasis on gravity- to ask whether I may be overestimating the negative outcome of enumerating a set of relatively specific requirements as a proxy for prohibiting 'neglect'. Does perhaps such an enumeration qualify as an adequate proxy once we take into account established legal tools designed specifically to remedy overand underinclusiveness?

Although the law is indeed capable of remedying some of the relevant errors, the answer-I think-is still no. The reason is that the relevant legal tools are subject to several significant limitations. The necessity_or "lesser evils" — defense, for example, which allows for acquittal in case the defendant's best course of action really was to break the law, is in general not known to people, and authorities arguably have an interest in keeping it that way. ${ }^{21}$ This means that circumstances in which subjects will do what is best-by breaking the law-are likely to be relatively rare. And even if people did know about the defense, they would presumably be very hesitant to take the risk and hope for a successful outcome. In fact, it seems that they should be hesitant, since-as Gideon Yaffe has pointed out - the calculation of lesser/greater evils is far from consistent between courts, because it is not settled (in any jurisdiction)

20. Thanks to a reviewer at Ethics for pressing me to highlight this aspect of being an adequate proxy.

21. For a discussion, see Meir Dan-Cohen, "Decision Rules and Conduct Rules: On Acoustic Separation in Criminal Law," in Harmful Thoughts: Essays on Law, Self, and Morality (Princeton, NJ: Princeton University Press, 2002), 37-93. 
what standards are to be employed in evaluating the alternatives or what it is exactly that needs to be better than what. ${ }^{22}$

In addition to all this, legal defenses can only mitigate the effects of overinclusion. But in the case of neglect, in contrast to most other legislative scenarios, ${ }^{23}$ underinclusion is arguably the more serious side of the coin (or at least equally serious), and the only possible way of mitigating underinclusion seems to be the employment of expansive purposive legal interpretation. But this presupposes that cases of underinclusion reliably reach the courts, and much has to happen for a case that is not covered by the law (but which should be) to get that far in the system. It is probably not an exaggeration to say that most cases of underinclusion will stay out of the courts' reach, and, as a result, judicial interpretation is a rather inefficient tool for dealing with underinclusion.

From all this, it seems to me appropriate to conclude that in the case of neglect, using a list of fairly specific action types is not an option that is available to lawmakers, given their end to adequately regulate the relevant form of conduct. I won't venture to define the threshold that - no doubt, vaguely - divides courses of action into means and nonmeans, relative to ends, but I do think we can say that, whatever that threshold is, using a set of fairly precise requirements just cannot be considered a means to adequately regulating conduct that is especially damaging to children. It is just too far off the mark.

As I have hinted at, I do not think that lawmakers are required to use the term 'neglect' undefined, as UK lawmakers, for example, did in the Children and Young Persons Act. ${ }^{24}$ It may well be that although no manageable list will count as an adequate proxy, some sort of approximating high-level definition will. In the United States, for example, the federal government provides a nonexhaustive definition of 'neglect' that constrains any state legislation: "the term . . . means, at a minimum, any recent . . . failure to act on the part of a parent or caretaker, which results in death, serious physical or emotional harm, sexual abuse or exploitation, or ... failure to act which presents an immi-

22. See esp. Gideon Yaffe, "A Procedural Rationale for the Necessity Defense," Iournal of Value Inquiry 43 (2009): 369-90, 372-78. I should note that Yaffe doubts that the necessity defense is best characterized as a justificatory defense. Rather, he thinks, it is a procedural estoppel defense, much like the defense of double jeopardy. If the government were to find the defendant guilty, its conduct would be "inconsistent in some way with some prior government conduct with respect to the defendant" (371), vis-à-vis its authority over her.

23. As Douglas Husak notes in his Overcriminalization: The Limits of the Criminal Law (Oxford: Oxford University Press, 2008), there is in law a presumption against overinclusion/ overcriminalization (see 154); such a presumption, however, can be justified only if overinclusion is generally worse than underinclusion.

24. See n. 15 . 
nent risk of serious harm" (my emphasis). ${ }^{25}$ To be sure, when nonexhaustive definitions are provided, they do not replace their definienda, and many states (such as California, Connecticut, and Kentucky) have followed the federal government in defining 'neglect' in this incomplete way (with some variation of course). ${ }^{26}$ However, several states (including New Jersey, Texas, and Utah) do provide what appear to be complete high-level definitions of 'neglect', that is, definitions that do replace the "ordinary meaning" of the term even if they are intended to capture or approximate it. ${ }^{27}$ Given these (seemingly adequate) proxies, what should we make of the claim that incommensurate multidimensionality - and, hence, vagueness - is necessary in order to adequately regulate conduct that is especially damaging to children?

The answer, I think, is this: for every way in which you can reasonably formulate a legal text that aims to adequately regulate conduct that is especially damaging to children, it is the case that, necessarily, if lawmakers enact a norm using a text formulated in that way, then the resulting law contains terms that are associated with multiple incommensurate dimensions and, hence, vague. Or, to put it another way, there are more or less general ways, as well as more or less informative ways, in which lawmakers might try to achieve the relevant purpose, but the law will be multidimensional - and therefore vague - no matter which one of them is chosen. In fact, I believe that in the case of neglect, the law will be extravagantly vague, just as Endicott claims, since any proposal that can be considered a means to the relevant end has to be multidimensional in much the same way as 'neglect'. The US definitions of 'neglect' mentioned in the previous paragraph are good examples of this. ${ }^{28}$ And multidimensionality of that sort entails extravagant vagueness, if Endicott is right.

I hope to have made a reasonable case for the claim that expressions that cover classes of widely varying conduct do so not in virtue of the fact that they are vague but rather in virtue of the fact that they are associated with multiple - and often incommensurate-dimensions. To be sure, the vagueness of the relevant terms is, by necessity, tied to their multidimensionality, but not in a way that makes vagueness central in our explanation of how the law can, or should, achieve regula-

25. See The Child Abuse Prevention and Treatment Act, 42 U.S.C. $§ \S 5101,5116$ et seq.

26. California Welf. \& Inst. Code § 300; Connecticut Gen. Stat. § 46b-120; Kentucky Rev. Stat. $\$ 600.020$.

27. New Jersey Ann. Stat. § 9:6-8.21; Texas Fam. Code $§ 261.001$; Utah Ann. Code $\S 78 \mathrm{~A}-6-105$.

28. Note that what makes these definitions multidimensional is not that they are disjunctive but rather that each disjunct contains a term associated with multiple (incommensurable) dimensions. 
tion of very broad classes of conduct. Rather, vagueness is a necessary consequence of the feature that actually does facilitate reference to these classes. To use vague terms, then, is something lawmakers have to do in order to achieve certain valuable ends-it is indeed a practical necessity in some sense-but that does not make their vagueness a means to those ends.

Next, I want to turn to what I take to be a broader payoff of the foregoing critique. It is a payoff, I think, that applies not just to Endicott's argument but also to a number of related arguments regarding the instrumental value of vagueness in the law. If I am correct, these arguments also wrongly attribute value to vagueness on the grounds that it is a means to some end that is valuable for law.

\section{WALDRON'S ARGUMENT FROM FACILITATION}

It is sometimes said that vagueness in the law can be a good thing because it enables lawmakers to enact norms that are "flexible," "openended," "elastic," or "adaptable." In a recent paper, for example, Jeremy Waldron says that open-ended standards invoke people's capacity for practical deliberation in both structured and unstructured ways - that is, it incentivizes them to act according to their own practical thinking in certain circumstances. ${ }^{29} \mathrm{~A}$ vague traffic provision, for example, may require one to make some appropriate-but unspecified-modification to one's driving behavior whenever a particular circumstance occurs. Such a provision thus relies on, and-if internalized-invokes, the capacity of human agents to determine what behavior is appropriate given the provision and the relevant circumstances. ${ }^{30}$ In doing so, Waldron says, the law directs subjects to consider a multitude of factors that may combine in various ways to determine what they ought - by lawto do. As he explains, a great variety of things - such as the narrowness of the roadway, the amount of traffic, and the presence of children playing on the road-may play a part in determining what modification a driver ought to make to her driving behavior, given a traffic provision requiring people to drive at a 'reasonable or proper' speed..$^{31}$

Our general capacity to deliberate about action in this way is, according to Waldron, a valuable one - in fact, it is what the dignity of a human agent consists in. The law, in issuing vague norms, he says, respects this dignity by "[crediting] the subject with the sophisticated ability to adapt [her] agency to [her] own practical thinking when this is

29. Jeremy Waldron, "Vagueness and the Guidance of Action," in Marmor and Soames, Philosophical Foundations of Language in the Law, 58-82.

30. Ibid., 64.

31. Ibid. 
required of [her]." ${ }^{32}$ In doing so, the law recognizes the moral standing that a person has in a society. ${ }^{33}$

On the basis of this, Waldron concludes about the value of vagueness in the law that "[it] is good to focus on the need for legislative flexibility [in certain areas]. . . . The adaptability of law, secured precisely by what others would call its indeterminacy, is . . . a valuable legislative resource and a respectful one too, for it works in tandem with the most sophisticated understanding of people's powers of practical reasoning." ${ }^{44}$ Thus, Waldron takes vagueness to be valuable for law on the grounds that enacting extravagantly vague norms makes the law flexible and open-ended, which in turn invokes a capacity the exercise of which realizes the dignity of human agents. According to Waldron, then, vagueness in the law is a good thing because it is a facilitating - or partial - means to invoking people's capacity for practical deliberation in a special way. ${ }^{35}$

In the interest of clarity, let us analyze Waldron's argument in the following way:

P1. Invoking people's capacity for practical deliberation in a way that realizes the dignity of human agents is good.

P2. Vagueness in the law is a facilitating - or partial - means to invoking people's capacity for practical deliberation in a way that realizes the dignity of human agents.

P3. Value transmits from ends to means. ${ }^{36}$

C. Vagueness in the law is (sometimes) instrumentally good. ${ }^{37}$

Structurally, the argument is nearly identical to Endicott's, except that the second premise is a claim about facilitating means, rather than necessary means. I will argue that Waldron's conclusion about the value of

32. Ibid., 65 .

33. Jeremy Waldron, "How Law Protects Dignity," Cambridge Law Journal 71 (2012): 200 222, 201-2. I should note that in Waldron's view, dignity is not a value concept but rather a status concept, designating what we he calls high-ranking social status. For the purposes of my discussion in this article, however, this difference is immaterial, since Waldron clearly believes that it is a good thing to assign such high rank to everyone and that it isconsequently — one of law's virtues that it facilitates and protects such an assignment.

34. Waldron, "Vagueness and the Guidance of Action," 82.

35. Thanks to a reviewer at Ethics for helpful comments on this section.

36. As in the case of Endicott's argument, I take P3 to transmit pro tanto value; see discussion in Sec. I.

37. Also as in the case of Endicott's argument, I take it that Waldron is assuming that the pro tanto goodness that vagueness in the law has is not outweighed by any pro tanto badness it may have. Alternatively, we can limit the conclusion to pro tanto goodness. 
vagueness in the law rests on a conflation of two distinct notions of flexibility and open-endedness, one properly associated with vagueness and the other with multidimensionality. If what I say is correct, the support for Waldron's instrumental premise (P2) goes away - we will have reason to be skeptical that vagueness is a means to invoking people's capacity for practical deliberation in the relevant way. Instead, as before, multidimensionality seems to be doing the work.

To be sure, as several authors have noted, vagueness in an important sense does allow for flexibility and open-endedness in the law. ${ }^{38}$ Sometimes, lawmakers - for various reasons - do not want to settle beforehand how to classify borderline cases. It is better to deal with them in the courts, if and when they come up, since that allows decision makers to evaluate, for each case, whether it (and sufficiently similar ones) should be within or outside the reach of the law (and for what reasons). This is indeed appropriately characterized as flexibility or open-endedness, and vagueness does help bring this about.

However, this is not the only way in which it is valuable that the law is flexible or open-ended. Often, the relevant-and usually more pressing - matter is that lawmakers do not want to draw sharp lines that make determinate cases fall on the wrong side of law's boundary, vis-àvis the relevant law's rationale. If there is an indefinite variety of ways, for example, in which one can neglect a child, the worry is not that using more specific language will arbitrarily settle borderline cases of neglect but rather - as we have seen - that some determinate cases of neglect will not be covered by law and that some determine cases of nonneglect will be. And this matter has to do with multidimensionality, rather than vagueness.

If we attend to why it is that terms like 'reasonable' invoke the deliberative capacity that Waldron appreciates, we see that his argument really concerns this latter notion of flexibility and open-endedness: "The legislature does not want [certain] norms pinned down to a precise and exact meaning that will govern all future cases; that would detract from the very elasticity that it is aiming at and it would detract from the sort of active consideration by citizens that it is seeking authoritatively to elicit. ... If someone asks about the meaning of 'reasonable' or 'appropriate', all we can do is indicate that these are flexible all-purpose predicates of evaluation that invite us to consider a number of possible factors in an open-ended way." 39 It may of course vary between legal contexts

38. See, e.g., Scott Soames, "Vagueness and the Law," in The Routledge Companion to Philosophy of Law, ed. Andrei Marmor (New York: Routledge, 2012), 95-108; and Asgeirsson, "Vagueness and Power-Delegation."

39. Waldron, "Vagueness and the Guidance of Action," 74; my emphasis. 
whether it is - ultimately - a good idea to rely on subjects themselves to make potentially complex judgments about what kind of behavior is required of them in particular circumstances. Perhaps it turns out that traffic provisions using terms like 'reasonable' and 'proper' are generally a bad idea, whereas it might - as we have seen-be a good idea to protect the interests of children using terms like 'neglect'. In Waldron's view, however, there appears to be something distinctly valuable in invoking the capacity of human agents to determine how they ought to behave, a value that is to some extent independent of considerations regarding the adequate regulation of conduct that eludes specification. A multidimensional traffic provision, for example, might turn out to be a bad idea all things considered, but it would still require people to act according to their own practical thinking and thereby help realize the dignity of human agents, on Waldron's account. Thus, if Waldron is right, there is something valuable about laws containing multidimensional terms even in cases in which such law is ultimately undesirable, a value deriving from the fact that it directs people to consider a multitude of possible factors in an open-ended way, in an effort to determine what they ought - by law - to do in the relevant circumstances.

Now, one might of course disagree with Waldron that invoking people's capacity for practical deliberation in this way genuinely realizes the dignity of human agents. That is, one might want to reject Waldron's P1. For the sake of argument, however, I am at least prepared to accept that it may be true. It may also be true that the value of employing terms like 'reasonable', 'proper', and 'neglect' in legal provisions has been underestimated, due to a failure to see how such provisions respect the dignity of human agency. However, even if both these claims were true, Waldron's conclusion about the value of vagueness in the law would not follow. The reason, I hope to have shown, is that the argument trades on a conflation of the two notions of flexibility and open-endedness mentioned above. Thus, Waldron-and whoever argues in a similar veinwrongly associates vagueness with an instrumental role that is really played by multidimensionality and, as a result, wrongly attributes instrumental value to vagueness, at least in significant part.

I should note that at a certain point in his paper, Waldron indicates that there is - so far as his argument is concerned-no need to distinguish between "unclarity, vagueness, and imprecision" or between "ambiguity, vagueness, and contestability." 40 One might think, therefore, that I am being somewhat uncharitable to Waldron-perhaps he is using the term 'vagueness' as we often do in ordinary conversation, to cover all sort of cases in which an utterance might provide insufficiently specific

40. Ibid., 62, esp. n. 16. 
information, relative to the purpose of the relevant conversation (broadly construed).

However, although it may be the case that Waldron is primarily using the term 'vague' in a broad sense, rather than the technical sense it has in logic and philosophy of language, I still think his argument is a fair target for my critique. The reason is that even if this is the case, his claim that there is - for the purposes of his argument-no need to distinguish between, for example, ambiguity, vagueness, and contestability clearly indicates that he thinks that vagueness in the technical sense is one of the sources of vagueness in the broader sense. But if that is the case, then introducing the former into the law is a facilitating means to doing so with the latter. Given the transitivity of the $i s-a$ means-to relation, it follows that vagueness in the technical sense is a facilitating means to invoking people's capacity for practical deliberation in a way that realizes the dignity of human agents, which is exactly P2 above. Further, since value transmits from ends to means, establishing that vagueness in the broad sense can be a good thing suffices to establish that vagueness in the technical sense can, too. Thus, I take it that Waldron really is concerned with the value of vagueness in the technical sense, despite the fact that he may also have something broader in mind.

As in Endicott's case, what I have said here does not decisively show that Waldron's P2 is false, but it gives us good reason to be skeptical. In any case, I hope to have showed that the premise is unsupported by the considerations discussed by Waldron.

\section{POSSIBLE REPLY: VAGUENESS REALLY IS A MEANS TO THE RELEVANT ENDS}

The most natural response to my critique of Endicott and Waldron would, I think, be to argue that, since incommensurate multidimensionality entails vagueness, using vague terms is really a necessary means to using multidimensional terms and that - given the transitivity of the isa-means-to relation - value therefore does in fact transmit from the relevant legislative ends to vagueness. If that is correct, then vagueness in the law is still instrumentally valuable, although its value is perhaps not as "immediate" as we might have thought.

This strategy certainly has some appeal, in particular in Endicott's case-evidenced, for example, by the intuitive force of the following claim: in order to adequately regulate conduct that is especially damaging to children, lawmakers have to use vague terms. If this statement of practical necessity strikes us as true - and I have argued that it shouldthen that seems to lend some support to the claim that vagueness is 
after all a necessary means to the relevant legislative end. Perhaps, necessary consequences of means to ends are also means to those endswhich, if true, vindicates the instrumental premises of the two arguments. Or so this line of response goes.

Despite its prima facie plausibility, I think we have good reason to think that this strategy won't work. As I hope to show, practical necessity sentences are not confined to expressing means-ends relations, even if they are perhaps most commonly used in that way, and so true statements of practical necessity don't suffice to guarantee transmission of value. The best explanation for this, I believe, is that it is not generally true that if something is a necessary consequence of a means to some end, then it is also a means to that end-not even if it is something that one has to do in order to achieve that end.

Let me borrow and adapt an example from Jaegwon Kim to substantiate these claims. ${ }^{41}$ Say that Meletus sees to it that Socrates dies. By doing so, he also sees to it that Xantippe becomes a widow. But there is no causal relationship between Socrates's dying and Xantippe's becoming a widow - the dependence is of another sort. ${ }^{42}$ Imagine also, for the sake of argument, that in order to protect the youth of Athens, Meletus has to see to it that Socrates dies. Given the relation between seeing to it that Socrates dies and seeing to it that Xantippe becomes a widow, Meletus also has to see to it that Xantippe becomes a widow in order to achieve his end-it is in some sense a practical necessity.

Suppose, then, that it is in fact valuable that Meletus sees to it that the youth of Athens are protected and that - consequently-it is valuable that he sees to it that Socrates dies. It would seem odd to say that, by the same token, it is valuable that Meletus sees to it that Xantippe becomes a widow. Although her fate is something that has to be brought about in order to achieve a valuable end, it is not a means to that endthere is no interesting relation between her being or not being a widow and the youth of Athens. Rather, Xantippes's becoming a widow is just a necessary by-product of something that does help bring the relevant end about: Socrates's dying. Hence, her fate seems to be a practical ne-

41. Jaegwon Kim, "Noncausal Connections," Nô̂s 8 (1974): 41-52.

42. This sort of dependency is often called Cambridge dependency; see, e.g., ibid. For those who don't like Kim-style events and prefer Davidson-style events instead, I can make the same point by arguing that value talk and reasons talk is intensional rather than extensional. This isn't very hard, since SDL assumes that only logically equivalent descriptions can be substituted for one another. So even if we have theoretical reasons for saying that the lawmakers' using an incommensurately multidimensional term is in fact identical with the lawmakers' using a vague term and the former is instrumentally valuable, it does not follow that the latter is also (since these events are identical without being logically equivalent). 
cessity to which no value transmits. And the best explanation for this, it seems to me, is that making Xantippe a widow is not a means to killing Socrates.

Vagueness, I want to claim, is to lawmakers much like Xantippe's becoming a widow is to Meletus. What is going on in law, on my account, is that by using terms with multiple incommensurate dimensions, lawmakers also use terms that are (extravagantly) vague. Thus, if the former is something that lawmakers have to do in order, say, to adequately regulate conduct that is especially damaging to children, then so is the latter. However, in order for value to transmit in the required way, practical necessity is not enough - vagueness must also in some relevant sense help bring about the relevant legislative ends. And vagueness, if I am right, is not doing any of the work relevant to Endicott's argument - that is, there is no relevant connection between the vagueness of the relevant terms and the ability of lawmakers to use them to adequately regulate the relevant forms of conduct.

Granted, the relationship between incommensurate multidimensionality and vagueness is tighter than the relationship between Socrates's dying and Xanthippe's becoming a widow_after all, had Socrates not been married, Xanthippe's fate would have been quite different. However, there are two general reasons why I don't think this affects my point. First, among the main general lessons to draw from the Xanthippe example is that it is not generally true that if something is a necessary consequence of a means to some end, then it is also a means to that end, because not all such consequences help bring about the relevant ends. This, I have tried to show, is the case with vagueness in the law - at least the kind discussed by Endicott. Neither does it directly help bring about the relevant legislative ends, nor does it do so indirectly - it is not the case that by using vague terms one helps bring about that one uses terms with multiple incommensurate dimensions. Second, if the relevant consequence in question isn't doing any instrumental work, then there is simply nothing in virtue of which it has instrumental value, relative to the end in question. And this explains, I submit, why value fails to transmit from the relevant regulatory ends to vagueness, just as it explains how value fails to transmit to Xanthippe's becoming a widow.

These considerations carry over straightforwardly to Waldron's case: if value doesn't generally transmit from ends to necessary consequences of necessary means, then we have no reason to expect that value transmits from ends to necessary consequences of merely facilitating-or partial-means. The reason, as before, is that it is not generally true that if something is a necessary consequence of a means to some end, then it is also a means to that end. This applies equally to necessary means 
and merely facilitating means and, thus, equally to the envisioned amendments of the two arguments.

\section{ANOTHER POSSIBLE REPLY: THE LOGIC OF VALUE VALIDATES CLOSURE UNDER NECESSARY CONSEQUENCE}

In the previous section, I was concerned with showing that it is not generally true that if something is a necessary consequence of a means to some end, then it is also a means to that end. On the assumption that value only transmits from ends to means, but not to necessary consequences of those means, this allowed me to resist the conclusion that vagueness in the law is a good thing. In this final section, I want to consider what implications it has for my arguments in this article that Standard Deontic Logic (SDL) validates closure under necessary consequence. ${ }^{43}$ Assuming we have at least a prima facie reason to expect the logic of 'good' to mirror the logic of 'ought' in significant (if not all) respects, the problem I face is that it makes sense to ask-given that I have conceded that incommensurate multidimensionality is sometimes a good thing - whether the logic of value forces on me the conclusion that vagueness is sometimes a good thing, too.

I don't think it does; there are a number of ways to block the inference, some of which require rejecting SDL and some of which do not. The purpose of this final section, however, is not to catalog the different possible responses but rather to acknowledge that-and illustrate how-in making claims about how to reason with value statements, one incurs significant commitments in the logic of value.

First, we could reject closure under necessary consequence for both the logic of 'ought' and the logic of 'good', which would amount to rejecting SDL altogether. This would not be a novel move-many authors have provided reasons for thinking that distribution over conjunction (from which closure under necessary consequence is crucially derived) is problematic in the case of 'ought'. In particular, many of the so-called paradoxes of deontic logic arise because of distribution over conjunction. ${ }^{44}$ These paradoxes can more or less be reproduced using value statements instead of ought statements, and so distribution over conjunction seems equally problematic in the logic of value. However, SDL happens to be a comparatively well-studied logic, being - as it is - a normal modal logic, and so this strategy entails a very significant com-

43. For a discussion of SDL, see, e.g., Risto Hilpinen and Dagfinn Føllesdal, "Deontic Logic: An Introduction," in Deontic Logic: Introductory and Systematic Readings, ed. Risto Hilpinen (Dordrecht: Reidel, 1971), 1-35.

44. For an overview of the paradoxes, see, e.g., Paul McNamara, "Deontic Logic," in Stanford Encyclopedia of Philosophy, ed. Edward Zalta (Stanford, CA: Stanford University, 2014), http:/ / plato.stanford.edu/archives/spr2014/entries/logic-deontic. 
mitment: to provide a workable logic for both 'ought' and 'good', alternative to SDL.

Second, we could claim that the logic of 'ought' is closed under necessary consequence but that the logic of 'good' is not. However, although it allows us to retain SDL, this second strategy generates even further commitments than the first, since we would incur a commitment both to provide a workable logic for 'good' that does not validate closure under necessary consequence and to explain why the logics of 'ought' and 'good' diverge so radically. To be sure, there are significant natural differences; for example, the phrase 'it is good that' is presumably factive, whereas 'it ought to be the case that' is not. However, although such a difference will of course make for a difference in the logics of the two notions, it is not so radical as to make one a normal modal logic and the other not.

Third, we could hold that the logic of intrinsic value is closed under necessary consequence but that the logic of instrumental value is not. And since we are here concerned with the instrumental value of vagueness, the problematic conclusion doesn't follow. Perhaps, necessary consequences of intrinsically good states of affairs are also themselves good, but the same is not true of states of affairs that are merely instrumentally good. This is an attractive strategy but would generate a commitment - in particular - to provide a workable logic of instrumental value, alternative to SDL.

Fourth, we could distinguish between types of value claims of the form 'it is good that $p$ ' and ' $x$ is good' and argue that only the former distributes over conjunction. Given my concession that it is good that lawmakers use terms that have multiple incommensurate dimensions, it would then follow that it is good that lawmakers use terms that are vague. This conclusion, however, tells us nothing about the value of vagueness, as such; it just tells us - to a rough approximation-that the possible worlds in which lawmakers use vague terms are better than some contextually determined standard or better than sufficiently many other possible worlds in some relevant comparison class. That is, while the conclusion does tell us something about the "normative status" of the relevant possible worlds, it doesn't tell us anything about in virtue of what they have that status. Thus, nothing follows about the value of vagueness, as such: on this account, that it is good that lawmakers use vague terms does not entail that vagueness is good. $^{45}$

As I said, the purpose of this final section is neither to catalog nor to thoroughly discuss the possible responses to the apparent problem posed by the attractiveness of closure under necessary consequence in

45. And - on this account - that incommensurate multidimensionality is good and that incommensurate multidimensionality entails vagueness do not together entail that vagueness is good. 
the logic of evaluative notions. It is important to emphasize, however, that in making claims about how to reason with value statements, one incurs deep commitments in logic. What I mean by this is not that deontic logic - or the logic of evaluation, more broadly - is somehow theoretically prior to value theory or theories of practical reasoning. Rather, I mean that logic serves as a significant constraint on such theories, in the sense that it counts significantly against a theory if the resulting logic proves unworkable. It should be clear, therefore, that limiting the principle of value transmission to the means-ends relationship - as I have done in this article - is not without significant further commitment. 